\title{
VALIDATION AND PHYSICAL PARAMETRIZATION OF A GAUSSIAN CLIMATOLOGICAL MODEL APPLIED TO A COMPLEX SITE
}

E. Runca

International Institute for Applied Systems Analysis, Laxenburg, Austria and

Istituto di Cosmogeofisica del CNR, Torino, Italy

\author{
A. Longhetto \\ Centro di Ricerca Termica e Nucleare dell'ENEL, Milano, Italy \\ and \\ Istituto di Fisica Generale dell'Università, Torino, Italy \\ G. Bonino \\ Istituto de Cosmogeofisica del CNR, Torino, Italy \\ and \\ Istituto di Fisica Generale dell'Università, Torino, Italy
}

RR-82-1

January 1982

Reprinted from Atmospheric Environment, volume 16(2) (1982)

INTERNATIONAL INSTITUTE FOR APPLIED SYSTEMS ANALYSIS

Laxenburg, Austria 
Research Reports, which record research conducted at IIASA, are independently reviewed before publication. However, the views and opinions they express are not necessarily those of the Institute or the National Member Organizations that support it.

Reprinted with permission from Atmospheric Environment 16(2):259-266, 1982.

Copyright (C) 1982 Pergamon Press Ltd.

All rights reserved. No part of this publication may be reproduced or transmitted in any form or by any means, electronic or mechanical, including photocopy, recording, or any information storage or retrieval system, without permission in writing from the copyright holder. 


\section{FOREWORD}

Mathematical models play an important role in devising and implementing policies aimed at conserving the quality of the environment. The complexity of environmental processes and the wide spectrum of scales that must be considered dictate not only that the structure of the models be clear and appropriate but also that their applicability to real situations be validated. The work of the International Institute for Applied Systems Analysis on environmental control and management addresses both of these issues.

As an example of these concerns, this paper not only discusses the model form but also how its applicability was validated, with a view to using the results to support actions to protect the atmospheric environment.

The paper deals with a simple model that simulates air pollution behavior in an area with complex topography where both urban and industrial activities contaminate the atmosphere. The parameters of this model were estimated from field experiments, and then its validity was tested by a variety of means. The authors conclude that their model can be used as a tool for planning and implementing air quality strategies in an appropriate area. Thus, their results can also help in planning urban and industrial development on a local scale.

JANUSZ KINDLER Chairman

Resources and Environment Area 


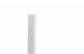




\title{
VALIDATION AND PHYSICAL PARAMETRIZATION OF A GAUSSIAN CLIMATOLOGICAL MODEL APPLIED TO A COMPLEX SITE*
}

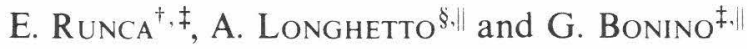 \\ (First received 17 November 1980 and in final form 17 February 1981)
}

\begin{abstract}
Seasonal $\mathrm{SO}_{2}$ average concentrations have been simulated in a topographically complex-coastal site, by means of a Gaussian type model. The model diffusion equation has been parametrized on the basis of the results from a series of field experiments conducted in the area to characterize the dynamic and thermodynamic properties of the local atmosphere. The validity of the adopted model formulation and physical parametrization has been discussed by comparing simulated and measured concentration values separately for unstable, neutral and stable situations, and by testing the model sensitivity with respect to changes in the parameters used. The analysis has shown that definition of the model physical parameters as indicated by the field experiments leads to a very satisfactory agreement between the calculated and measured concentrations. Therefore the model can be considered a suitable tool to implement air quality strategies in the area on a climatological basis. The study has been applied to the complex coastal site of La Spezia, Italy, for the period March 1975-February 1977.
\end{abstract}

\section{INTRODUCTION}

The assumption that the distribution of gaseous pollutants in a plume is Gaussian has constituted a basis for many studies of computation of air pollutant concentrations. Although there have been examples of Gaussian models applied to the simulation of short term (hourly-daily) average concentration (see e.g. Shieh et al., 1972) the Gaussian concept is mainly considered adequate for long term (month-season) average times (see e.g. Martin, 1971; Calder, 1971; Prahm and Christensen, 1977; Runca et al., 1976).

Air pollution models applied to the simulation of long-term average concentration are also named climatological models. Since the development of an industrial and/or urban area must guarantee a low exposure (i.e. a low long term average concentration) to air pollution for all the points in the area of interest, these models provide a substantial help to planners and decision makers. However, the credibility of Gaussian climatological models is not well established, especially in application to topographically complex sites. This is, to a large extent, due to the inadequacy of model parameters to actually represent the physical situations under which pollutant dispersion occurs.

In order to verify the applicability of the Gaussian concept to a topographically complex situation and to study the physical factor which could be included in the model to improve simulation results, seasonal

* This work was partially supported by "Progetto Finalizzato per la Promozione della Qualità dell'Ambiente" of C.N.R.

$\dagger$ IIASA, Schloss Laxenburg, 2361, Laxenburg, Austria.

¥ Istituto di Cosmogeofisica del CNR - C. so Fiume, 4, Torino, Italy.

$\S$ Centro di Ricerca Termica e Nucleare dell'ENEL, Milano, Italy.

|| Istituto di Fisica Generale dell'Università, Torino, Italy. average concentrations of $\mathrm{SO}_{2}$ have been simulated and compared with measured values in the basin of $\mathrm{La}$ Spezia in Italy by means of a Gaussian climatological model.

The La Spezia basin was chosen as an optimal area in which to conduct the study due to the availability of detailed information concerning the local meteorology. This information was provided by a series of field experiments (Anfossi et al., 1979) carried out in the area jointly by the ENEL-C.R.T.N. (Italian National Electricity Company-Nuclear and Thermal Research Center) and the C.N.R.-I.C.G. (National Council of Research-Cosmogeophysics Institute) from 1974 to 1978. As shown below, the physical information from the results of the field experiments was relevant to the implementation of the model.

A description of the model application is given by Bonino et al.(1980). In the present work, after summarizing the data used and the model structure, measured and simulated three-monthly $\mathrm{SO}_{2}$ concentrations for the period Feb. 1975-Jan. 1977 are compared. A sequence of validation tests is then performed to analyze the effects of the adopted physical parametrization on the results given by the model. In order to check to which extent the statistical averaging of errors affects the agreement between measured and computed concentration values, the model results, in this analysis, are also computed and compared with measurements, separately for the stability situation (A-B), (C-D) and (E-F), defined according to Pasquill (1974).

$$
\text { 2. DATA }
$$

\subsection{The La Spezia basin}

The study has been conducted on the La Spezia basin which is illustrated in Fig. 1 derived from a 


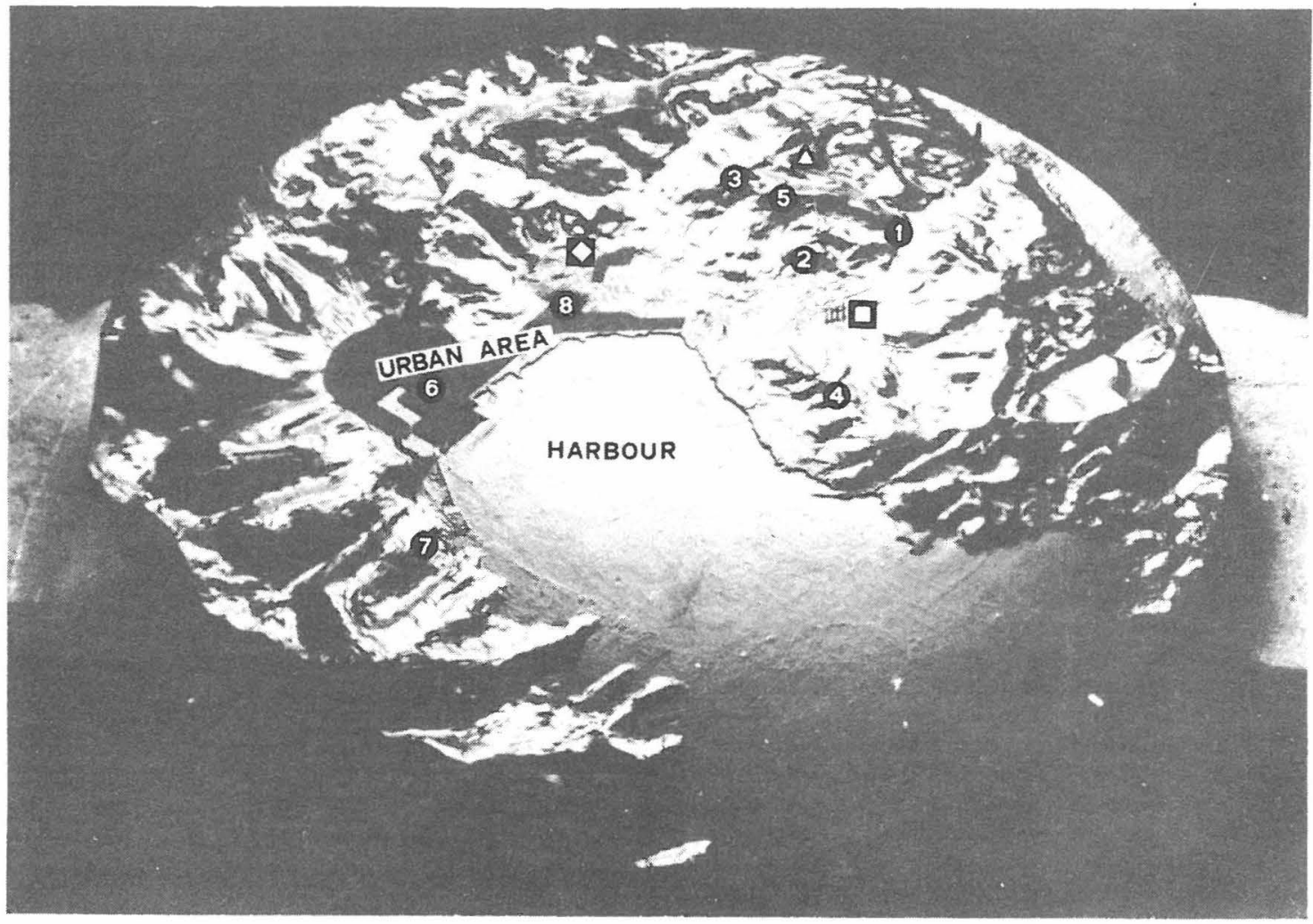

Fig. 1. Picture of tridimensional plastic model of the area. Symbols denote: $\mathbf{Q}$, power plant; $\mathbf{Z}$, refinery; ( $\mathbf{0}$-(8) monitoring stations; $\Delta$, meteorological station.

picture of a model of the area. The basin is located on the Northwest coast of the Italian Riviera on the upper part of the Tyrrhenian sea. Its natural bay lies on the Tyrrhenian sea; it extends from Northwest to Southeast, and it is surrounded by a hilly terrain which reaches a maximum height of $500 \mathrm{~m}$. Northwest of the bay, between the coast and the hills, is a flat area where the city of La Spezia and its harbour are located.

\subsection{Meteorological and concentration data}

As a result of harbour, industrial and urban activities, the air quality of the site has deteriorated during the last few years. In order to monitor the local pollution situation an air quality monitoring network has been located in the area by ENEL. The network (see Fig. 1) consist of 8 stations recording $\mathrm{SO}_{2}$ concentration and two meteorological stations. Both the concentration and the meteorological data are automatically transmitted to a small computer and memorized as semi-hourly average values. Of the two meteorological stations, one located in the city and the other at $226 \mathrm{~m}$ above sea level (Mt. Beverone station), only the data recorded by the latter have been used in this study as they were considered more adequate for description of the transport of air pollutants over the La Spezia basin.

\subsection{Results from the field experiments}

The complexity of the topography of the La Spezia basin influences the local micrometeorology and consequently the local air pollution dynamics. In order to improve the understanding of some of the meteorological factors relevant to air pollution and to evaluate the dispersion parameters to be used in the area for releases from elevated chimneys, six field experiments, each lasting 15 days, were carried out from 1974 to 1978. The findings from these field experiments have been described elsewhere (Anfossi et al., 1976; Anfossi et al., 1979; Santomauro et al., 1978; Bonino et al., 1980). However, a short summary of the physical conditions relevant to the model is given below.

The wind in the area is prevailingly blowing from North and from South. Although the local orography creates channeling effects and during sunny days a seabreeze flow is superimposed on the synoptic circulation, in general, the wind directions recorded by standard instrumentation can be considered as the ones along which, over a long averaging time, the transport of pollutants occurs.

During clear nights a ground based inversion develops over the land. The time evolution of the nocturnal inversion height $Z_{i}(\mathrm{~m})$ was experimentally found to grow according to the formula $Z_{i}=70 \sqrt{t}$, where $t(\mathrm{~h})$ is the time elapsed since $1.5 \mathrm{~h}$ before sunset. (Anfossi et al., 1979).

In the morning the growth of the convective layer was shown to follow (Anfossi et al., 1976) the model described by Carson (1973) and Carson and Smith 
(1974). The sea breeze circulation which is established after the erosion of the nocturnal inversion was also proved to maintain (Anfossi et al., 1976) an unstable layer (Van der Hoven layer, Van der Hoven, 1976) which was generally capped by an elevated inversion at approximately $500 \mathrm{~m}$. The above findings on the thermodynamic behaviour of the boundary layer were included in the model by imposing that during unstable situations the upward motion of pollutant matter was inhibited at $500 \mathrm{~m}$, while during stable situations the downward diffusion of pollutants was inhibited at the height of the nocturnal inversion. For the situations recorded as neutral or weakly unstable, it was assumed that neither nocturnal nor diurnal inversion occurred.

The field experiments were also organized to determine the dispersion parameters of pollutants released from elevated sources. Balloon trajectories were tracked for each of the six Pasquill stability conditions. The trajectories (Santomauro et al., 1978) were then used to estimate the vertical and horizontal standard deviations of the diffusing pollutants. These dispersion parameters were used in the model for the elevated chimneys.

\subsection{Emission data}

Final information required to apply the model concerns the $\mathrm{SO}_{2}$ emission distribution and rate. It was evaluated by dividing the sources into the three following classes: (a) industrial; (b) urban and (c) sources due to the harbour activities.

The industrial sources included in the model were the refinery operating in the area and the local power plant. The urban and harbour ones were represented by 62 and 12 equivalent point sources respectively (Bonino et al., 1980)

\section{DIFFUSION EQUATION AND PARAMETERS}

\subsection{Equation}

Assuming that :(a) on long term averaging times pollutant distribution is uniform in the crosswind direction in every sector of the wind rose (Calder, 1971); (b) the vertical pollutant distribution is Gaussian and (c) ground and inversion layers are impermeable barriers to air pollutant, the diffusion equation of the model can be put in the following form:

$$
\begin{aligned}
& C_{p}=\frac{N}{(2 \pi)^{3 / 2}} \sum_{k}^{M} \frac{Q_{k}}{D_{p, k}} \sum_{\substack{\mathrm{id}, \mathrm{iw} \\
\text { is, it }}} \frac{F(\mathrm{id}, \mathrm{iw}, \text { is, it })}{u \text { iw, is, it) } \sigma_{z}\left(D_{p, k}, \text { is }\right)} . \\
& \cdot \sum_{n=-\infty}^{n=\infty}\left\{\exp \left[-\frac{\left(z_{p}-h_{k}(u, t, \text { is })+2 n L\right)^{2}}{2 \sigma_{z}^{2}\left(D_{p, k}, \text { is }\right)}\right]\right. \\
& \left.+\exp \left[-\frac{\left(z_{p}+h_{k}(u, t, \text { is })+2 n L\right)^{2}}{2 \sigma_{z}^{2}\left(D_{p, k}, \text { is }\right)}\right]\right\}
\end{aligned}
$$

where $C_{p}=$ concentration* at receptor point

\footnotetext{
* Reduced to N.T.P.
}

$\left(\mu \mathrm{g} \mathrm{m}^{-3}\right) ; N=$ number of wind rose sectors ( 8 in this study); $M=$ number of point sources; $Q_{k}=$ emission rate of the $k^{\text {th }}$ source $\left(\mu \mathrm{g} \mathrm{s}^{-1}\right) ; D_{p, k}=$ distance of point $p$ from the $k^{\text {th }}$ source projected on the wind direction (m); $F$ (id, iw, is, it) = frequency of wind blowing into a given $45^{\circ}$ sector of the wind rose (id), for a given wind speed class (iw), atmospheric stability class (is) and temperature class (it); $\mathrm{u}$ (id, iw, is, it) = average wind speed corresponding to the meteorological situation having frequency $F$ (id, iw, is, it); $\sigma_{z}=$ vertical standard deviation of the diffusing particle $(\mathrm{m}) ; z_{p}=$ receptor point height $(\mathrm{m}) ; h_{k}=$ height of the plume axis "(geometric stack height + plume rise) (m); $t$ (id, iw, is, it) = average temperature corresponding to the meteorological situation having frequency $F$ (id, iw, is, it) $\left({ }^{\circ} \mathrm{C}\right) ; L=$ inversion layer height (m).

According to this equation, the seasonal average concentration at receptor point $p$ is the sum of the contribution of the $M$ sources due to the meteorological conditions recorded in the area, each multiplied by its frequency of occurrence in the considered season.

The joint frequency meteorological distribution was derived from the data recorded at $\mathrm{Mt}$. Beverone station by taking eight wind directions, six atmospheric stability according to Pasquill-Gifford, the following five classes for wind velocity: $1-2 ; 2-3.5 ; 3.5-5.5 ; 5.5-8.5$ and greater than $8.5 \mathrm{~m} \mathrm{~s}^{-1}$, and the following four classes for temperature: $<0 ; 0-10 ; 10-20$ and greater than $20^{\circ} \mathrm{C}$. Temperature is included in the joint frequency meteorological distribution to account for the effect of buoyancy on the plume rise.

The implemented Gaussian equation is a modification of the formulation originally proposed by Pooler (1961) and successively applied in more or less modified form, by many authors (see e.g. Martin, 1971; Calder, 1971; Prahm and Christensen, 1977 and Runca et al., 1976).

\subsection{Physical parametrization}

In comparison with the formulation used by Runca et al. (1976), the one adopted here and in the previous study by Bonino et al. (1980), includes the effects on dispersion due to diurnal and nocturnal inversion. The former is taken into account by means of an infinite number of image sources (in the application only the first eight image sources were considered); the latter by assuming that pollutants released above the height of nocturnal inversion (calculated as described in section 2.3) cannot penetrate through it.

In order to take somewhat into account the complex topography of the area the concentration is computed at the height ( $z_{p}$ in the equation) above sea level of the monitoring stations. In general this choice is not the proper one as the relative position of the pollutants trajectories and the underlying surface is affected by the hill characteristics of the terrain. However in this study, considering the distribution of the sources and the topography of the area (see Fig. 1), colocation of the receptor points at their height above sea level appeared to be the most reasonable assumption. Also 


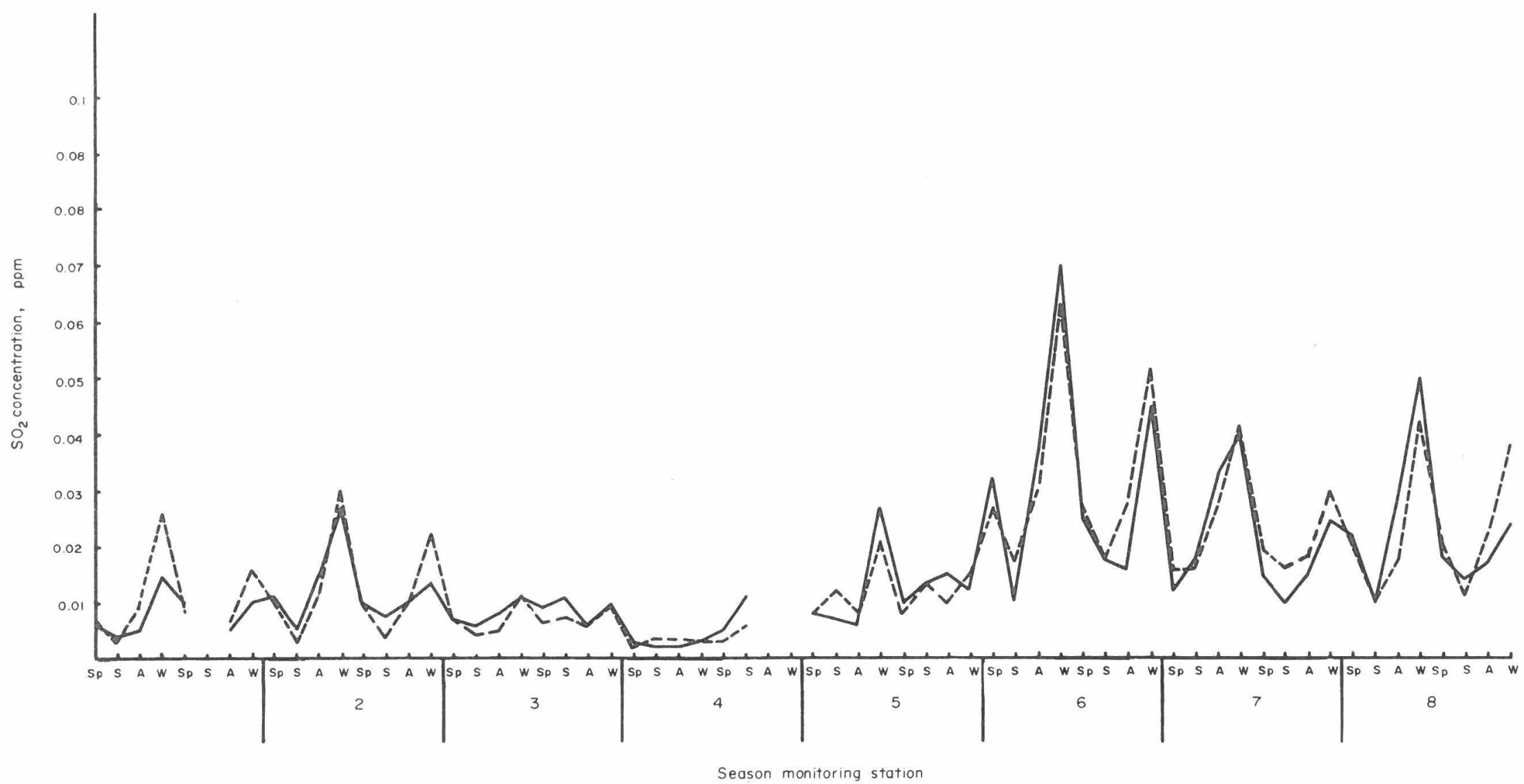

Fig. 2. Measured and simulated seasonal average $\mathrm{SO}_{2}$ concentration at monitoring stations:

-measured values; ------- simulated values. 1-8 indicate the monitoring stations (see Fig. 1). For each station the seasonal trend (from March 1975 to February 1977) of measured and calculated values is shown (Sp: Spring, S: Summer, A: Autumn, W: Winter). 
numerical tests showed that this choice gave the best agreement between simulated and measured values.

Evaluation of the dispersion parameter $\sigma_{z}$ was done as discussed in the data section for the industrial emission. The $\sigma_{z}$ values proposed by Pasquill and Gifford (see e.g. Gifford, 1975) have been used for the low sources. In order to take into account the turbulent mixing introduced by the urban roughness and thermal effects these $\sigma_{z}$ values have been moved of one class towards instability for the stable situation (see e.g. Runca et al., 1976; Prahm and Christensen, 1977).

Evaluation of the plume rise of the power plant stacks, done during the above mentioned field experiments, showed (Anfossi et al., 1976) that the best fit for single source was given by the Briggs' (1969) plume rise equations. Briggs' formulas were then used for the power plant emissions, while Concawe model (see e.g. Detrie, 1969) was used for the refinery plumes as no experimental data were available for these emissions. The height of urban and harbour emmissions were taken constant (Bonino et al., 1980).

\section{MODEL VALIDATION}

Seasonal $\mathrm{SO}_{2}$ average concentrations have been computed by the model for eight seasons from March 1975 to February 1977, i.e. for the period for which both emission and meteorological data were available. The seasons have been defined as follows: Spring $=$ March, April and May; Summer = June, July and August; Autumn = September, October and November; Winter $=$ December, January and February.

Simulated and measured values in the eight stations are plotted in Fig. 2. The agreement is very satisfactory, The model correctly describes both the seasonal pollution pattern and the $\mathrm{SO}_{2}$ spatial distribution in every season. Stations 1 and 4 being out of order respectively during Summer 1976 and AutumnWinter 1976 were not considered. For the data of Fig. 2 the correlation coefficient is equal to 0.9 ; slope and intercept of the regression line (simulated vs measured) are 0.89 and $0.002 \mathrm{ppm}$, respectively.

Although the correlation coefficient does not provide an absolute way to evaluate the model, the value obtained here is considered high even for models applied to situations simpler than the one of La Spezia. (The regression line shows that the model slightly underestimates the highest concentration values and overestimates the lowest concentration values.)

The results achieved with the choosen physical parametrization of the model could be due to statistical averaging of errors. In order to establish the credibility of the model the analysis described below has been carried out.

Seasonal concentration values occurring separately with the stability conditions $(\mathrm{A}-\mathrm{B}),(\mathrm{C}-\mathrm{D})$ and $(\mathrm{E}-\mathrm{F})$ have been simulated and compared with the corresponding measured values. Correlation and regression line coefficients for these cases and for the other considered in this analysis are reported in Table 1.

The lowest correlation coefficient is found for the unstable situation, the highest for the stable situation. However, if in those situations recorded as stable the effect of the nocturnal inversion described in section 2.3 had not been considered the correlation coefficient would have dropped from 0.92 to 0.71 , the intercept of the regression line would have risen from $0.002 \mathrm{ppm}$ to $0.018 \mathrm{ppm}$ and the slope would have become larger than 1 . The model, therefore, would strongly overestimate the measured concentration values as shown in Fig. 3.

The result given by the model for stability $(E-F)$ in addition to considering the nocturnal inversion were obtained by moving the $\sigma_{z}$ values applied to the low sources of one class toward instability as discussed in section 3.2. If this condition had not been imposed, the

Table 1. Correlation coefficient, slope and intercept of the regression line for the cases illustrated in the first column

\begin{tabular}{lccc}
\hline $\begin{array}{l}\text { Considered } \\
\text { cases }\end{array}$ & $\begin{array}{c}\text { Correlation } \\
\text { coefficient }\end{array}$ & $\begin{array}{c}\text { Reg. Line: } \\
\alpha\end{array}$ & $\begin{array}{c}C_{\text {sim }}=\alpha C_{\text {meas }}+\beta \\
\beta(\mathrm{ppm})\end{array}$ \\
\hline $\begin{array}{l}\text { Reference } \\
\text { case }\end{array}$ & 0.90 & 0.89 & 0.002 \\
$\begin{array}{l}\text { Stability } \\
\text { (A-B) }\end{array}$ & 0.75 & 0.61 & 0.005 \\
$\begin{array}{l}\text { Stability } \\
(\mathrm{C}-\mathrm{D})\end{array}$ & 0.83 & 0.87 & 0.002 \\
$\begin{array}{l}\text { Stability } \\
\begin{array}{l}\text { E-F) } \\
\text { Stability E-F } \\
\text { (no nocturnal inv.) }\end{array}\end{array}$ & 0.92 & 1.03 & 0.003 \\
$\begin{array}{l}\text { Stability E-F } \\
(\sigma\end{array}$ & 0.71 & 1.05 & 0.018 \\
$\begin{array}{l}\text { Reference case } \\
(\sigma \text { Briggs })\end{array}$ & 0.93 & 1.43 & -0.002 \\
\hline
\end{tabular}

The reference case is the one of Fig. 2. The others differ from the reference case either in considering only those situations with a given atmospheric stability or in modifying some of the parameters used in the reference case. 


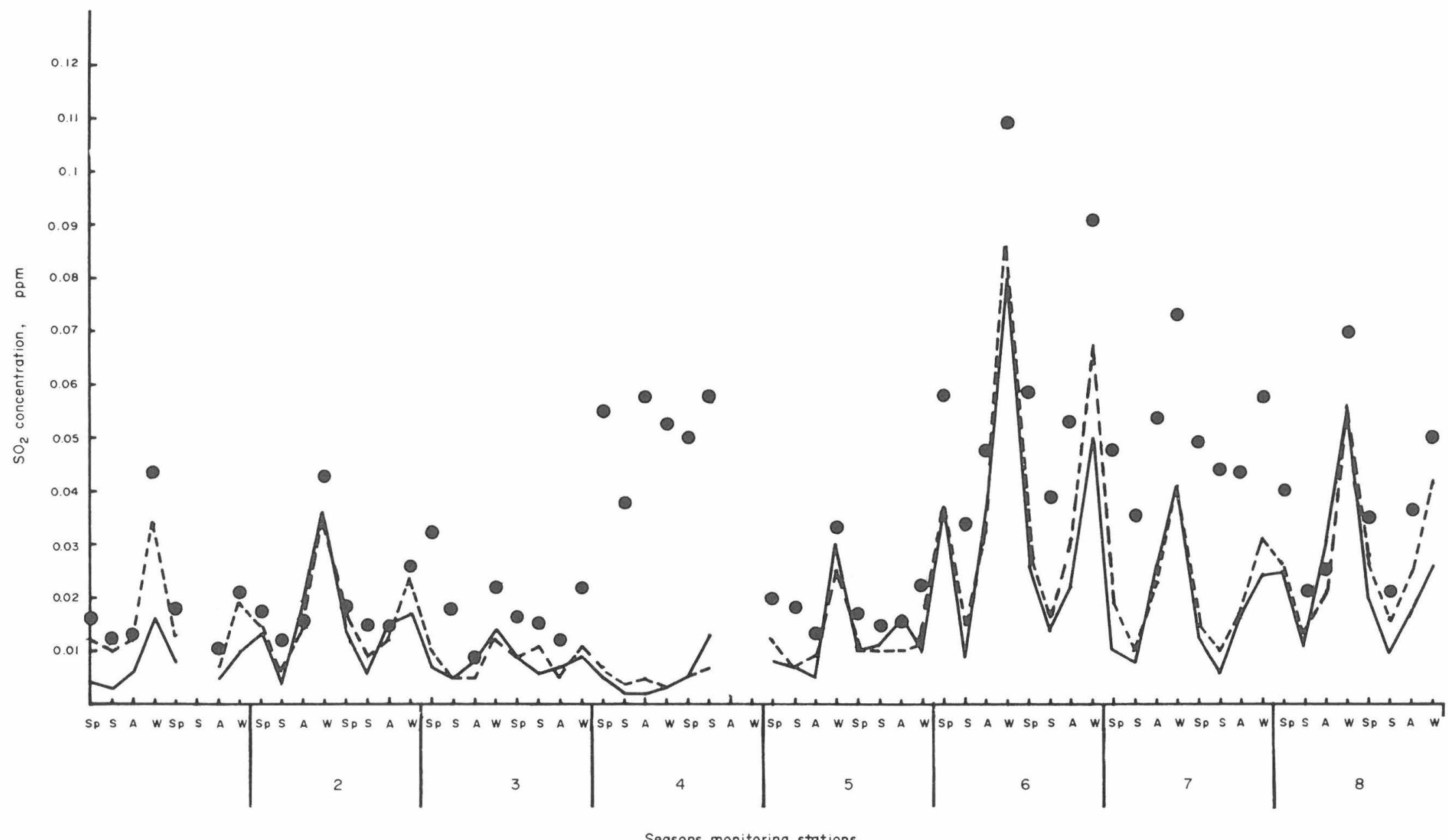

Fig. 3. Measured and simulated $\mathrm{SO}_{2}$ concentration at monitoring stations for $\mathrm{E}$ and $\mathrm{F}$ stability categories: - measured values, ---.-- simulated values; $\bigcirc$ simulated values without nocturnal inversion condition. Abbreviations as in Fig. 2. 
model, as shown by the slope and intercept of the regression line (see Table 1), would have strongly overestimated the highest concentration values and slightly underestimated the lowest concentration values. Since the largest concentrations occur in the stations located in or in proximity of the urban area, this result confirms that the dilution of pollutants in an urban area is greater than in an open country due to the increased turbulent mixing introduced by urban aerodynamic roughness and thermal effects. The correlation coefficient however is as high as for the case in which the $\sigma_{z}$ values were moved of one class toward instability. This indicates from one side that there is basic agreement between the model and the real process, from another side that the correlation coefficient, as already said, cannot be taken as the only estimator of the credibility of the model.

The latter consideration can be extended to all the cases considered in Table 1 . The correlation coefficients reported in Table 1 range from 0.71 to 0.93 and thus the model appears to be a true representation of the real process. The validity of this representation is due to the introduction into the model of some of the physical factors which are relevant to the process (such as the nocturnal inversion condition) and on the refinement of some parameters.

The model has been also run by replacing for the low sources the dispersion parameters given by Pasquill-Gifford with the ones proposed by Briggs for urban emissions (see Gifford, 1975). In agreement with the previous considerations the correlation coefficient remained satisfactorily high. The low sensitivity of the correlation coefficient to dispersion parameters was also reported by Prahm and Christensen (1977). The slope of the regression line, however, dropped to 0.55 indicating a strong increase of the deviations between measured and simulated values. Due to this result the utilized dispersion parameters appeared to be a very suitable choice for this study.

A final comment on the validity of the adopted physical parametrization concerns the introduction of the diurnal inversion in the model. Simulations without this condition proved that it had very little influence on the concentration field. Given that this condition mostly influences the contribution to concentration from the elevated sources, this result was expected as a consequence of the relative closeness of the tall chimneys to the receptor points and to the inadequacy of the diffusion equation described in section 3.1 to represent the complexity of vertical mixing in unstable situations (see e.g. Lamb, 1978).

\section{CONCLUSION}

A Gaussian climatological model has been applied to the simulation of seasonal $\mathrm{SO}_{2}$ average concentration in the La Spezia basin, Italy.

The validity of the model has been discussed by analyzing the results separately for different atmospheric stabilities, and by testing the model sensitivity to changes in the adopted parametrization. The validation analysis showed that the model simulates correctly concentration values in unstable as well in neutral and stable situations, and that any modification of the choosen parametrization resulted in an increase of the deviations between measured and simulated values.

In the tests performed the largest variations occurred for the slope and the intercept of the regression line, while the correlation coefficient always mantained an acceptable high value. The explanation for this fact is in the proportional relationship which exists between sources and concentration measured in the downwind receptors (see e.g. Gifford and Hanna, 1973). The correct choice of this relationship is fundamental to the implementation of a diffusion model. Thus, geometry and strength of the sources and wind are the basic factors affecting the correlation coefficient. Improvement of the agreement between the model and reality, in the sense of reduction of the deviation between measured and calculated concentration, can then be achieved by refining the physical parametrization of the model.

The application of the above concepts has been possible in this study due to the availability of detailed information on the local meteorology deduced from a series of field experiments. This has led to a very satisfactory agreement between the simulated and measured concentrations for the analyzed eight threemonthly periods from March 1975 to February 1977, and has proved that a Gaussian climatological model can simulate seasonal pollution in a topographically complex site as the one of La Spezia, Italy. This model can therefore, be used as a tool to implement air quality strategies on a climatological basis.

\section{REFERENCES}

Anfossi D., Bacci P., Bonino G., Briatore L., Elisei O., Giraud C., Longhetto A., Piano A. and Richiardone R. (1979) Aerologia di un sito costiero complesso: il Golfo di La Spezia. Published by Consiglio Nazionale delle Ricerche, Roma, Ref. Colonna del P. F. Promozione della Qualità dell'Ambiente, AQ/3/3.

Anfossi D., Bacci P., Giraud C., Longhetto A. and Piano A. (1976) Meteorological survey at La Spezia site. Proc.Tenth Int. Colloquium, pp. 531-540, Paris, France. Elsevier, Amsterdam.

Bonino G., Longhetto A. and Runca E. (1980) A physical approach to air pollution climatological modelling in complex site. Nuovo Cim. 3C (in press).

Briggs G. A. (1969) Plume rise. USAEC, Div. of Tech. Info., TID-25075.

Calder K. L. (1971) A climatological model for multiple source urban air pollution, pp. I1-I33, NATO/CCMS, Air Pollution Rep. $\mathrm{n}^{\circ} 5$.

Carson D. J. (1973) The development of a dry inversioncapped convectively unstable boundary layer. $Q$. Jl R. met. Soc. 99, 450-467.

Carson D. J. and Smith F. B. (1974) Thermodynamic model for the development of a convectively unstable boundary layer. Adv. Geophys. 18A, 111-124.

Detrie J. P. (1969) La Pollution Atmospheric. Dunod, Paris. Gifford F. A. and Hanna S. R. (1973) Modelling urban air 
pollution. Atmospheric Environment 7, 131-136.

Gifford F. A. (1975) Atmospheric dispersion models for environmental pollution applications. Lectures on Air Pollution and Environmental Impact Analysis A. M. S. pp. 35-58.

Lamb R. G. (1978) A numerical simulation of dispersion from an elevated point source in the convective planetary boundary layer. Atmospheric Environment 12, 1297-1304.

Martin D. O. (1971) An urban diffusion model for estimating long term average values of air quality. J. Air Pollut. Control Ass. 21, 16-19.

Pasquill F. (1974) Atmospheric Diffusion. Halsted Press, John Wiley, New York.

Pooler F. (1971) A prediction model of mean urban pollution for use with standard wind roses. Int. J. Air Water Pollut. 4, 199-211.
Prahm L. P. and Christensen M. (1977) Validation of a multiple source Gaussian air quality model. Atmospheric Environment 11, 791-795.

Runca E., Melli P. and Zannetti P. (1976) Computation of long-term average $\mathrm{SO}_{2}$ concentration in the Venetian area. Appl. Math. Mod. 1, 9-15.

Santomauro L., Bacci P., Longhetto A., Anfossi D. and Richiardone R. (1978) Experimental evaluation of diffusion parameters on a local scale by means of no-lift balloons. $J$. appl. Met 17, 1441-1449.

Shieh L. J., Halpern P. K., Clemens B. A., Wang H. H. and Abraham F. F. (1972) Air quality diffusion model: application to New York City. I.B.M. J. Res. Devl. 16, 162170.

Van der Hoven I. (1976) Atmospheric transport and diffusion at coastal sites. Nucl. Saf. 8, 490-499. 


\title{
RELATED IIASA PUBLICATIONS
}

\author{
RESEARCH REPORTS
}

The Smeared Concentration Approximation Method: A Simplified

Air Pollution Dispersion Methodology for Regional Analysis R.L. Dennis

Assessment of Alternative Energy/Environment Futures for Austria 1977-2015

W.K. Foell, R.L. Dennis, M.E. Hanson, L.A. Hervey,

A.H. Hoelzl, J.P. Peerenboom, E. Poenitz

Real-Time Forecasting of Air Pollution Episodes in the Venetian

Region. Part 1: The Advection-Diffusion Model

E. Runca, P. Melli, A. Spirito

Part II: The Kalman Predictor

G. Fronza, A. Spirito, A. Tonielli

Real-time control of sulphur dioxide emissions from an industrial area

P. Melli, P. Bolzern, G. Fronza, A. Spirito

Reprinted from Atmospheric Environment, Vol. 15, 1981, pp. 653-666

\section{COLLABORATIVE PAPERS}

Statistical Analysis of Winter Sulphur Dioxide Concentration Data in Vienna

P. Bolzern, G. Fronza, C. Überhuber

An Analysis of Finite Difference and Galerkin Techniques applied to the Simulation and Diffusion of Air Pollutants from a Line

Source

E. Runca, P. Melli, F. Sardei

\section{WORKING PAPERS}

A practical numerical algorithm to compute steady-state ground level concentration by a $K$-model

E. Runca

(To be published in Atmospheric Environment)

Crop Yields in $\mathrm{CO}_{2}$-enriched Atmosphere

P. Kauppi 


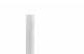




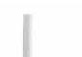

